\title{
Functionalized Graphene-based Polyamide Thin Film Nanocomposite Membranes for Organic Solvent Nanofiltration
}

Lorena Paseta ${ }^{\mathrm{a}}$ José Miguel Luque-Alled ${ }^{\mathrm{b}}$, Magdalena Malankowska ${ }^{\mathrm{a}}$, Marta Navarro ${ }^{\mathrm{a}}$, Patricia Gorgojo $^{\mathrm{b}}$, Joaquín Coronas ${ }^{\mathrm{a}}$ and Carlos Téllez ${ }^{\mathrm{a}, *}$

${ }^{a}$ Chemical and Environmental Engineering Department, Instituto de Nanociencia de Aragón (INA) and Instituto de Ciencia de Materiales de Aragón (ICMA), Universidad de Zaragoza-CSIC, 50018 Zaragoza, Spain.

${ }^{\mathrm{b}}$ School of Chemical Engineering and Analytical Science, University of Manchester, M13 9PL, United Kingdom

\section{* Corresponding author:}

Prof. Carlos Téllez

Chemical and Environmental Engineering Department, Instituto de Nanociencia de Aragón (INA) and Instituto de Ciencia de Materiales de Aragón (ICMA), Universidad de Zaragoza-CSIC, 50018 Zaragoza, Spain.

Phone: +34 9767628 97. Fax: 34976761879 .

e-mail: ctellez@unizar.es 


\section{ABSTRACT}

This work deals with the use of octadecylamine (ODA)-functionalized reduced graphene oxide (rGO) for thin film nanocomposite (TFN) membranes. The functionalization of rGO with ODA leads to graphene-based nanofillers, more hydrophobic than GO, and thus to the easier dispersion in the organic phase of the interfacial polymerization (IP) reaction carried out to produce polyamide (PA) TFN membranes. The performance of the new TFN membranes is evaluated by organic solvent nanofiltration (OSN) of alcoholic solutions containing dyes Acridine Orange (AO, MW $265 \mathrm{~g} \cdot \mathrm{mol}^{-1}$ ), Sunset Yellow (SY, MW $452 \mathrm{~g} \cdot \mathrm{mol}^{-1}$ ) and Rose Bengal (RB, MW $\left.974 \mathrm{~g} \cdot \mathrm{mol}^{-1}\right)$. The functionalized nature of the nanoparticles introduced into the hydrophilic PA layer allow an increase of the ethanol permeance from 2.8, 3.4 and $3.7 \mathrm{~L} \cdot \mathrm{m}^{-2} \cdot \mathrm{h}^{-1} \cdot \mathrm{bar}^{-1}$ for AO, SY and RB, respectively, corresponding to the bare thin film composite membrane (without rGO-ODA particles) to $4.3,4.6$ and $6.0 \mathrm{~L} \cdot \mathrm{m}^{-2} \cdot \mathrm{h}^{-1} \cdot \mathrm{bar}^{-1}$ for $\mathrm{AO}, \mathrm{SY}$ and $\mathrm{RB}$, respectively, for the rGO-ODA based TFN membrane. In fact, we hypothesize that the increase of the ethanol flux achieved with the use of rGO-ODA as a filler in TFN membranes is owing to a combination of the simultaneous presence of polar and non-polar groups from rGO-ODA nanosheets and the creation of still selective narrow gaps between these particles and the polyamide (PA).

Keywords: Organic solvent nanofiltration, GO-based materials, octadecylamine, thin film nanocomposite membrane, dye rejection 


\section{Introduction}

The term "nanofiltration" (NF) was first used in 1984 [1] and according to the pore size of species that can be rejected it lies between ultrafiltration (UF) and reverse osmosis (RO). Nanofiltration has been widely used in water treatment [2-4], replacing in some cases RO processes as it also shows high rejections but lower pressures that are needed to obtain similar fluxes. This translates into a lower energy demand [5]. In recent years, this pressure-driven process has attracted widespread interest for its application in molecular separations in organic media (coined as organic solvent nanofiltration, i.e. OSN) thanks to the economical, safety and environmental advantages that it offers [6] in comparison to the more traditional separation processes like distillation. Besides, it has been already implemented in some industrial processes like the Max-Dewax process developed by Exxon Mobile for solvent lubricant dewaxing, recovery of homogeneous hydroformylation catalysts used in the production of aldehydes [7] and extraction of rosmarinic acid (biological active) from rosemary [8].

Thin film composite (TFC) membranes, first developed by Cadotte [9] in the 80's, are the membranes pointed to replace the commonly used ISA (integrally skinned asymmetric) membranes used in both aqueous NF and OSN [10]. Such TFC membranes consist of an asymmetric polymeric support (usually fabricated by phase inversion on a non-woven support that gives them their mechanical stability) coated with a selective thin film skin layer that is usually synthesized by interfacial polymerization (IP) or by dip coating. This two-step process offers the advantage of optimizing each layer independently depending on the application requirements [11].

In 2007, Jeong et al. [12] aiming to improve the performance of polyamide TFC membranes in $\mathrm{RO}$, introduced zeolite $\mathrm{NaA}$ nanoparticles during the interfacial polymerization reaction; an increase in water permeance without sacrificing the rejection 
in comparison to the bare TFC membranes was obtained. Since then, these membranes, known as thin film nanocomposite (TFN) membranes, have been synthesized using different nanoparticles as fillers: $\mathrm{TiO}_{2}$ [13], MCM-41 silica [14], graphene oxide (GO) [15] and metal-organic frameworks (MOF) $[16,17]$ and they have been used in numerous RO and NF investigations, and even in gas separation applications [18].

Generally derived from the exfoliation of oxidized graphite, graphene oxide (GO) is an atom thick material with a two dimensional (2D) structure composed by $\mathrm{sp}^{2}$ carbon atoms bonded forming a hexagonal honeycomb framework [19]. Thanks to its extraordinary thermal, mechanical, optical and electrical properties [20], GO has become an interesting material in diverse fields such as sensors [21], catalysis [22], energy storage [23], separations [24] and biomedical applications [25]. GO and GO-derivatives have been widely used as fillers in the fabrication of gas $[24,26]$ and liquid $[27,28]$ phase separation membranes. Regarding liquid phase applications, TFN membranes containing graphene derivatives have been mainly produced for aqueous applications (RO, NF, and hydrophilic pervaporation) and pervaporation (PV). Chae et al. [27] fabricated TFN membranes using GO as a filler and obtained membranes with better antifouling properties and higher water fluxes in RO. Song et al. [29] observed similar results together with better chlorine resistance by the use of GO quantum dots as a filler. Wang et al. [30] used ZIF-8/GO hybrid nanosheets as fillers in the fabrication of antimicrobial TFN membranes which have shown an important antimicrobial activity enhancement. Ma et al. [31] synthesized TFN membranes using GO functionalized with poly(sulfobetaine methacrylate) and applied them in nanofiltration obtaining an increment in water flux as well as an enhancement in the antimicrobial activity and antifouling properties in comparison with TFC membranes. Xue et al. [32] improved the flux and the chlorine resistance of TFC membrane in the nanofiltration of salts in water by the fabrication of 
TFN membranes using GO-ODA (octadecylamine) as a filler. There are very few studies on the use of graphene-based fillers in thin film composite membranes for organophilic filtrations. Very recently Alberto et al. [33] developed TFN membranes for nbutanol/water separation by pervaporation embedding GO-derivatives into a high free volume thin film polymer matrix, which led to an enhancement in the separation performance as compared to the bare TFC membranes.

In this paper we report the preparation of polyamide (PA) based TFN membranes using reduced alkyl-functionalized GO (rGO) nanofillers and, as a novelty, such membranes can be used for organic solvent nanofiltration. The functionalization of rGO with ODA leads to graphene-based nanofillers which are more hydrophobic than non-functionalized GO, and thus better dispersed in the organic phase of the IP reaction. The rGO-ODA nanofillers are introduced at 0.03 and $0.06 \%(\mathrm{w} / \mathrm{v})$ concentrations in the organic solution used for the IP. The performance of the developed TFN membranes for nanofiltration of alcoholic solutions containing dyes of increasing molecular weights (Acridine Orange, Sunset Yellow and Rose Bengal) is evaluated. The functionalized nature of the rGO nanoparticles introduced into the hydrophilic PA layer is expected to raise the permeance of organic solvents through the TFN membranes.

\section{Experimental Section}

\subsection{Materials}

Graphite was purchased from NGS Naturegraphit GmbH (Germany). Sulfuric acid (95\%), octadecylamine (ODA, 99\%), hydrazine monohydrate $(98 \%)$, hexanediamine (HDA, 98\%), m-phenylenediamine (MPD, 99\%) and trimesoyl chloride (TMC, 98\%) were purchased from Sigma Aldrich. Dimethylsulfoxide (DMSO, 99.5\%), isopropanol (IPA, 99.5\%), polyethylene glycol (PEG, synthesis grade) and hexane (extra pure) were acquired from Scharlab. Potassium nitrate $\left(\mathrm{KNO}_{3}, 99 \%\right)$ and potassium permanganate 
$\left(\mathrm{KMnO}_{4}, 99 \%\right)$ was procured from Alfa Aesar. All the chemicals were used as obtained without any purification.

\subsection{Synthesis of reduced octadecylamine-functionalized Graphene Oxide}

GO was synthesized via a modified Hummers' method and subsequently alkylfunctionalized and reduced following a previously reported method [34]. A suspension of the as-synthesized GO $\left(1.45 \mathrm{mg} \cdot \mathrm{mL}^{-1}\right)$ was diluted with deionized water to a concentration of $1 \mathrm{mg} \cdot \mathrm{mL}^{-1}$ and sonicated for $1 \mathrm{~h}$. A solution of octadecylamine (ODA) was prepared dissolving $1.5 \mathrm{mmol}(404 \mathrm{mg})$ in $20 \mathrm{~mL}$ of ethanol. Once the ODA was dissolved, this solution was poured into the GO suspension and stirred at $60{ }^{\circ} \mathrm{C}$ for $12 \mathrm{~h}$. Afterwards, $220 \mu \mathrm{L}$ of hydrazine monohydrate diluted in $10 \mathrm{~mL}$ of water was added and stirred at $90{ }^{\circ} \mathrm{C}$ for $2 \mathrm{~h}$. Finally, the solution obtained was filtrated, washed several times with deionized water and ethanol and dispersed in $150 \mathrm{~mL}$ of hexane. The obtained powder is herein after referred as to rGO-ODA.

\subsection{Preparation of polyimide (PI) supports.}

The polyimide (PI) supports were prepared as follows: a dope solution of $24 \%(\mathrm{w} / \mathrm{w})$ was prepared by dissolving $\mathrm{P} 84^{\circledR}$ (HP polymer $\mathrm{GmbH}$ ) in DMSO and stirring overnight. Once dissolved, the solution obtained was allowed to stand until the air bubbles disappeared. The solution was then cast on a polypropylene non-woven backing material at a casting speed of $0.04 \mathrm{~m} \cdot \mathrm{s}^{-1}$ using a casting knife set at a thickness of $250 \mu \mathrm{m}$. Immediately after casting, the membrane was immersed in a deionized water bath, where the phase inversion occurred. After $10 \mathrm{~min}$, the membrane was transferred to a fresh water bath and left for 1 h. The wet membrane was then immersed in two consecutive baths of IPA for $1 \mathrm{~h}$ each to remove any residual water or DMSO. The support was cross-linked by immersing in a $120 \mathrm{~g} \cdot \mathrm{L}^{-1}$ solution of HDA in IPA for $16 \mathrm{~h}$ at $20{ }^{\circ} \mathrm{C}$ under stirring. Next, the membrane was washed with IPA four times for $1 \mathrm{~h}$ each to remove any traces of HDA. Finally, the 
support was immersed in a solution with a 3:2 volume ratio of PEG:IPA overnight under stirring to prevent pore collapse during the IP reaction. Finally, the PI support was wiped dry with tissue paper.

\subsection{Preparation of TFC and TFN membranes.}

The polyamide (PA) ultrathin layer was formed on cross-linked PI P84® supports by interfacial polymerization (IP) at room temperature. First, two solutions were prepared: an aqueous solution of $2 \%(\mathrm{w} / \mathrm{v})$ of MPD and a solution of $0.1 \%(\mathrm{w} / \mathrm{v})$ of TMC in a mixture of hexane (HPLC grade, VWR international) and ethanol in proportion 99.5/0.5\%. Next, a $60 \mathrm{~cm}^{2}$ support was placed in a glass filtration holder for the IP reaction and $20 \mathrm{~mL}$ of the aqueous solution was added. After $2 \mathrm{~min}$, the excess solution was removed and the membrane's surface was dried with a tissue paper. Next, $20 \mathrm{~mL}$ of the TMC solution was added and left for $1 \mathrm{~min}$, and after that $10 \mathrm{~mL}$ of fresh hexane was poured to stop the reaction. Then, the excess was removed and another $10 \mathrm{~mL}$ of hexane was added to further remove unreacted TMC. Finally, $10 \mathrm{~mL}$ of water was added to wash out the hexane and the TFC membrane formed was stored in deionized water in the fridge at ca. $5{ }^{\circ} \mathrm{C}$ and tested within $48 \mathrm{~h}$ of preparation.

For the preparation of the TFN membranes the same procedure was followed with the addition of two different loadings of rGO-ODA $(0.03 \%(\mathrm{w} / \mathrm{v})$ and $0.06 \%(\mathrm{w} / \mathrm{v}))$ in the organic phase (hexane/ethanol) before the IP reaction. In order to favor the rGO-ODA dispersion, the TMC solution was sonicated for $30 \mathrm{~min}$. Given the hydrophobic character of this filler its dispersion in the aqueous phase for the interfacial polymerization would not be desirable.

\subsection{Characterization of nanofillers and membranes.}


X-ray diffraction measurements were performed using an Empyrean PANalytical diffractometer with a $\mathrm{Cu}-\mathrm{K}_{\alpha}$ radiation source $(\lambda=1.5406 \AA)$. Data were collected in the $2 \theta$ range from $2.5^{\circ}$ to $40^{\circ}$ and at a scanning rate of $0.01^{\circ} \cdot \mathrm{s}^{-1}$.

Thermogravimetric analyses (TGA) were carried out in order to confirm the ODA functionalization of the GO. A Mettler Toledo DSC-1 Star System at a heating rate of 10 ${ }^{\circ} \mathrm{C} \cdot \mathrm{min}^{-1}$ up to $700{ }^{\circ} \mathrm{C}$ under an air flow of $80 \mathrm{~cm}^{3}(\mathrm{STP}) \cdot \mathrm{min}^{-1}$ was used.

Scanning electron microscope (SEM) images of the rGO-ODA and the surface of the membranes were obtained with FEI-Inspect F20 microscope operating at a voltage of 10 $\mathrm{kV}$. All samples were coated with $\mathrm{Au} / \mathrm{Pd}$ under vacuum conditions prior to analysis. Transmission electron microscopy (TEM) was carried out to check the presence and distribution of rGO-ODA and its interaction with the PA polymer network. In order to be able to detach the PA thin film nanocomposite layer from the PI P84® support for TEM observation, a $0.06 \% \mathrm{w} / \mathrm{v}$ rGO-ODA TFN membrane was synthesized over a noncrosslinked P84® support. This TFN membrane was immersed in N,Ndimethylformamide (DMF) at room temperature for $5 \mathrm{~min}$ to dissolve the PI P84® porous support. The resulting freestanding PA top layer was placed onto a carbon mesh grid and observed under a FEI Tecnai T20 transmission electron microscope operated at $200 \mathrm{kV}$. To confirm the successful functionalization and reduction of GO, attenuated total reflectance Fourier transform infrared spectroscopy (ATR-FTIR) was carried out. The analysis was performed in a Bruker Vertex 70 FTIR spectrometer equipped with a DTGS detector and a Golden Gate diamond ATR accessory in the $600-4000 \mathrm{~cm}^{-1}$ wavenumber range with a resolution of $4 \mathrm{~cm}^{-1}$. This technique was also applied to the TFN membranes to detect the presence of rGO-ODA nanofillers. For this purpose, the TFN membrane spectra were compared to that of rGO-ODA powder. 
The conversion of GO into rGO-ODA was also corroborated by Raman spectroscopy using a WiTec Alpha 300 confocal Raman microscope, with a $488 \mathrm{~nm}$ laser excitation beam. This technique was also used to verify the presence of the rGO-ODA into the PA layer in a small piece of the top layer detached during IP. TFC and TFN membranes were characterized by water contact angle measurements using a Krüss DSA $10 \mathrm{MK} 2$ at $20^{\circ} \mathrm{C}$ in up to three different areas for each membrane.

\subsection{Membrane performance.}

Organic solvent nanofiltration (OSN) was performed in a stirred dead-end membrane filtration cell (Sterlitech HP4750). The OSN performance of the developed TFN membranes and TFC control membranes was evaluated for three independent ethanol solutions containing three solutes with increasing molecular weights: Acridine Orange (AO, $265 \mathrm{~g} \cdot \mathrm{mol}^{-1}$, Across Organics, 55\%), Sunset Yellow (SY, $452 \mathrm{~g} \cdot \mathrm{mol}^{-1}$, Sigma Aldrich, 90\%) and Rose Bengal (RB, $974 \mathrm{~g} \cdot \mathrm{mol}^{-1}$, Sigma Aldrich, 95\%). Three membranes were measured. The feed solutions had a dye concentration of $20 \mathrm{mg} \cdot \mathrm{L}^{-1}$. The effective area of the membrane was $12 \mathrm{~cm}^{2}$ and the feed volume was $250 \mathrm{~mL}$. All experiments were carried out at a pressure of 20 bar and at room temperature. The rejection and the permeate flux were calculated by the following Equation 1 and Equation 2:

(Equation): $\quad$ Permeance $=\frac{V}{A \times t \times \Delta P}\left[\frac{L}{m^{2} \cdot h \cdot b a r}\right]$

(Equation): $\quad$ Rejection $(\%)=\left(1-\frac{C_{\text {permeate }}}{C_{\text {retentate }}}\right) \times 100$

where $V$ is the volume $(\mathrm{L}), A$ is the nanofiltration area of the membrane $\left(\mathrm{m}^{2}\right), \mathrm{t}$ is the time for the permeate collection (h) and $\Delta P$ is the pressure gradient used. Permeate and retentate aliquots $(3 \mathrm{~mL})$ were collected in each filtration once the flux was stable. Ethanol was allowed to completely evaporate in a fume hood and it was replaced by $3 \mathrm{~mL}$ of deionized water. The concentrations of permeate $\left(C_{\text {permeate }}\right)$ and retentate $\left(C_{\text {retentate }}\right)$ were 
measured by UV spectrometer (Shimazdu UV-2700) using water as a solvent. In the case of the aqueous filtrations, $C_{\text {permeate }}$ and $C_{\text {retentate }}$ were measured from the as-collected samples. The wavelengths of maximum absorbances of RB, SY and AO were $549 \mathrm{~nm}$, $480 \mathrm{~nm}$ and $490 \mathrm{~nm}$, respectively. Prior to NF, two post-treatments were applied to the membrane: first, a 10 min bath in DMSO followed by a DMSO filtration at 20 bar during $10 \mathrm{~min}$. This procedure has been reported as effective for the activation of the PA layer for the permeation of organic solvents [35].

\section{Results and Discussion}

\subsection{Characterization of $r G O-O D A$}

The nanoparticles used as fillers for the preparation of TFN membranes are usually added to the organic phase prior to the interfacial polymerization $[15,17,36]$. In consequence, it is necessary to have a good dispersion of the rGO-ODA nanofillers in the n-hexane phase to minimize the formation of agglomerates during the PA formation which would generate defects in the filler-polymer interface. GO is highly dispersible in water and in some polar solvents but unfortunately not in non-polar solvents like n-hexane [37]. Some strategies to improve its dispersibility in non-polar solvents include its reduction [38] or functionalization with alkylamines [39]. However, reduced graphene oxide is in practice immiscible with most organic solvents due to differences in cohesive energies of rGO and dispersible media, hence its functionalization can improve its dispersibility [40]. In this work, GO was functionalized with ODA and further reduced to obtain rGO-ODA (Figure 1a). To confirm this functionalization, further characterization was carried out. 

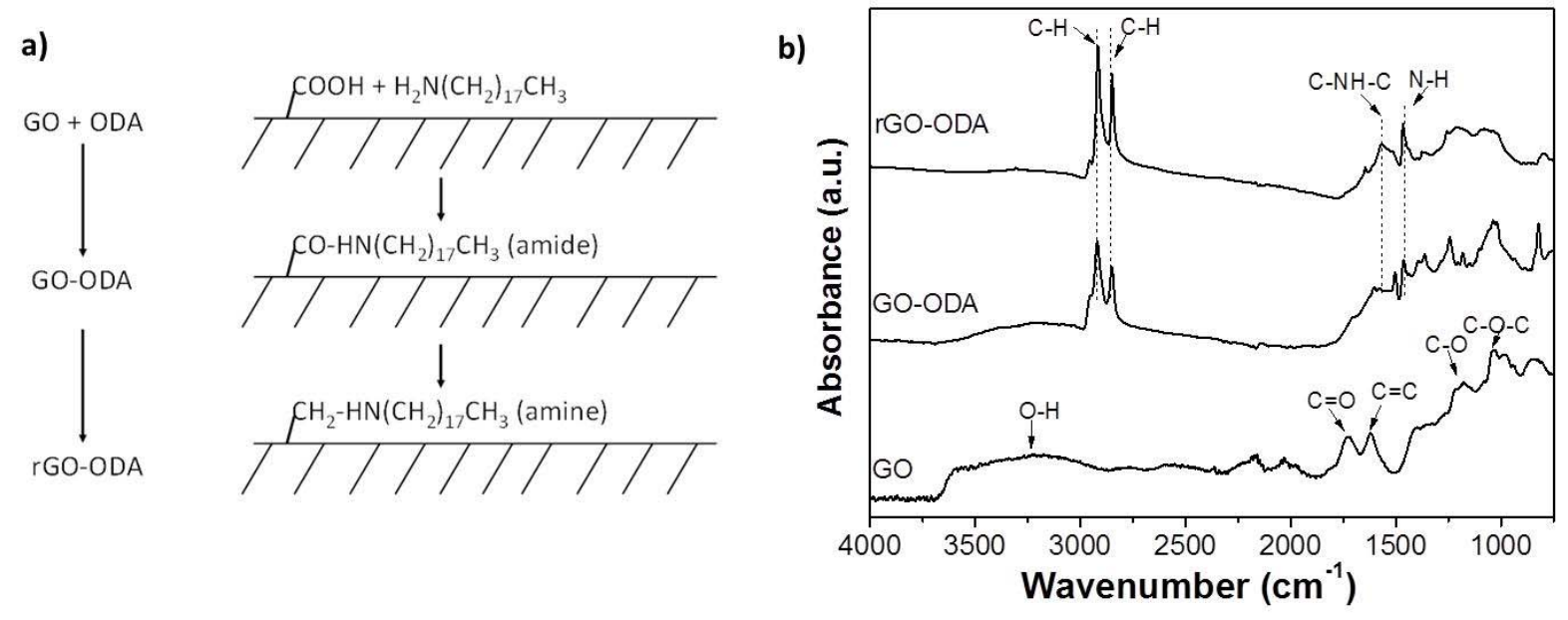

Figure 1. a) Scheme of the functionalization and reduction of GO. b) ATR-FTIR spectra of GO, GO-ODA and rGO-ODA.

ATR-FTIR was performed in order to verify the GO functionalization. Figure $1 \mathrm{~b}$ shows the spectra of the GO, GO-ODA and rGO-ODA. The typical peaks of GO appear at 1029 $\mathrm{cm}^{-1}, 1173 \mathrm{~cm}^{-1}, 1621 \mathrm{~cm}^{-1}, 1728 \mathrm{~cm}^{-1}$ and $3220 \mathrm{~cm}^{-1}$ related to alkoxy C-O stretching, epoxy $\mathrm{C}-\mathrm{O}$ stretching, $\mathrm{C}=\mathrm{C}$ stretching, $\mathrm{C}=\mathrm{O}$ carboxyl stretching and $\mathrm{O}-\mathrm{H}$ stretching, respectively. In the case of GO-ODA and rGO-ODA, two new peaks appear at $2916 \mathrm{~cm}^{-}$ ${ }^{1}$ and $2848 \mathrm{~cm}^{-1}$ corresponding to the alkyl C-H stretching. Another new peak is shown at $1564 \mathrm{~cm}^{-1}$ due to the $\mathrm{N}-\mathrm{H}$ stretching, and a final peak at $1466 \mathrm{~cm}^{-1}$ corresponding to the $\mathrm{C}-\mathrm{N}$ stretch of the amide, indicating the formation of $\mathrm{C}-\mathrm{N}-\mathrm{C}$ bonds between the alkylamine and GO [41].

Figure $2 \mathrm{a}$ exhibits the XRD patterns of GO, GO-ODA and rGO-ODA. The peak at $10.8^{\circ}$ of GO indicates an interlayer spacing of $0.8 \mathrm{~nm}$, which is in concordance with other results reported in literature [42]. In contrast, GO-ODA and rGO-ODA show main peaks at $4.4^{\circ}$ and $5.2^{\circ}$, respectively, which corresponds to interlayer spacings of $2 \mathrm{~nm}$ and 1.7 $\mathrm{nm}$, according to Bragg's law. These enlargements indicate that the alkyl chains of ODA were intercalated into the GO gallery spaces, in agreement with GO functionalization. In 
addition, GO-ODA and rGO-ODA patterns have a less intense and broad peak at around $21.4^{\circ}$ that suggests that the samples are poorly ordered along the stacking direction due to exfoliation [43].
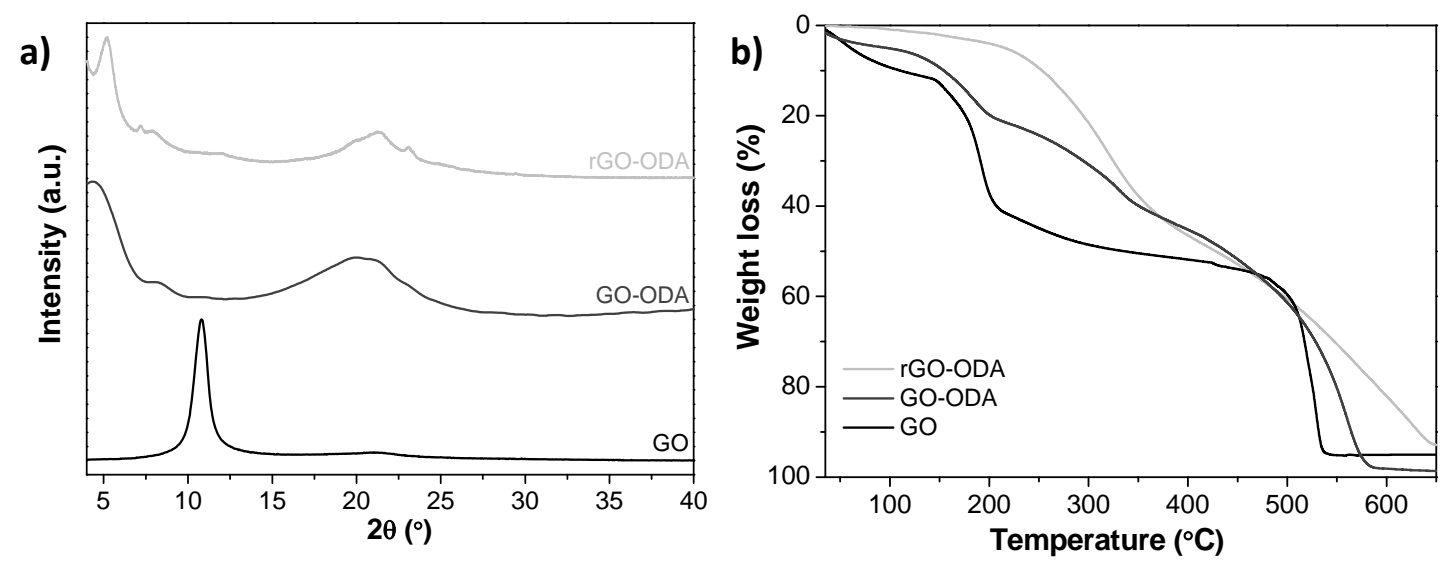

Figure 2. a) XRD patterns of GO, GO-ODA and rGO-ODA powder samples. b) TGA curves for GO, GO-ODA and rGO-ODA.

Figure 3 shows the Raman spectra of GO, GO-ODA and rGO-ODA. The three spectra exhibit two noticeable peaks at $\approx 1350 \mathrm{~cm}^{-1}$ and $\approx 1600 \mathrm{~cm}^{-1}$, corresponding to the socalled D and G bands, respectively. The ratio between the intensities of D and G bands $\left(\mathrm{I}_{\mathrm{D}} / \mathrm{I}_{\mathrm{G}}\right)$ expresses the $\mathrm{sp}^{3} / \mathrm{sp}^{2}$ carbon ratio, i.e. the degree of structural disorder. This ratio is 0.96 for both GO and GO-ODA whereas in the case of rGO-ODA is 0.98 . The same ratio of $\mathrm{I}_{\mathrm{D}} / \mathrm{I}_{\mathrm{G}}$ for $\mathrm{GO}$ and GO-ODA indicates that the functionalization with ODA has been carried out by the substitution of the existing oxygen-containing functionalities in GO. In the case of rGO-ODA, this ratio should decrease for the reduction of GO-ODA although in our case it is almost constant given the small difference. As justified in other works $[44,45]$, this discrepant result may be due to the fact that new graphitic domains were created smaller in size than those present in GO but more numerous. 


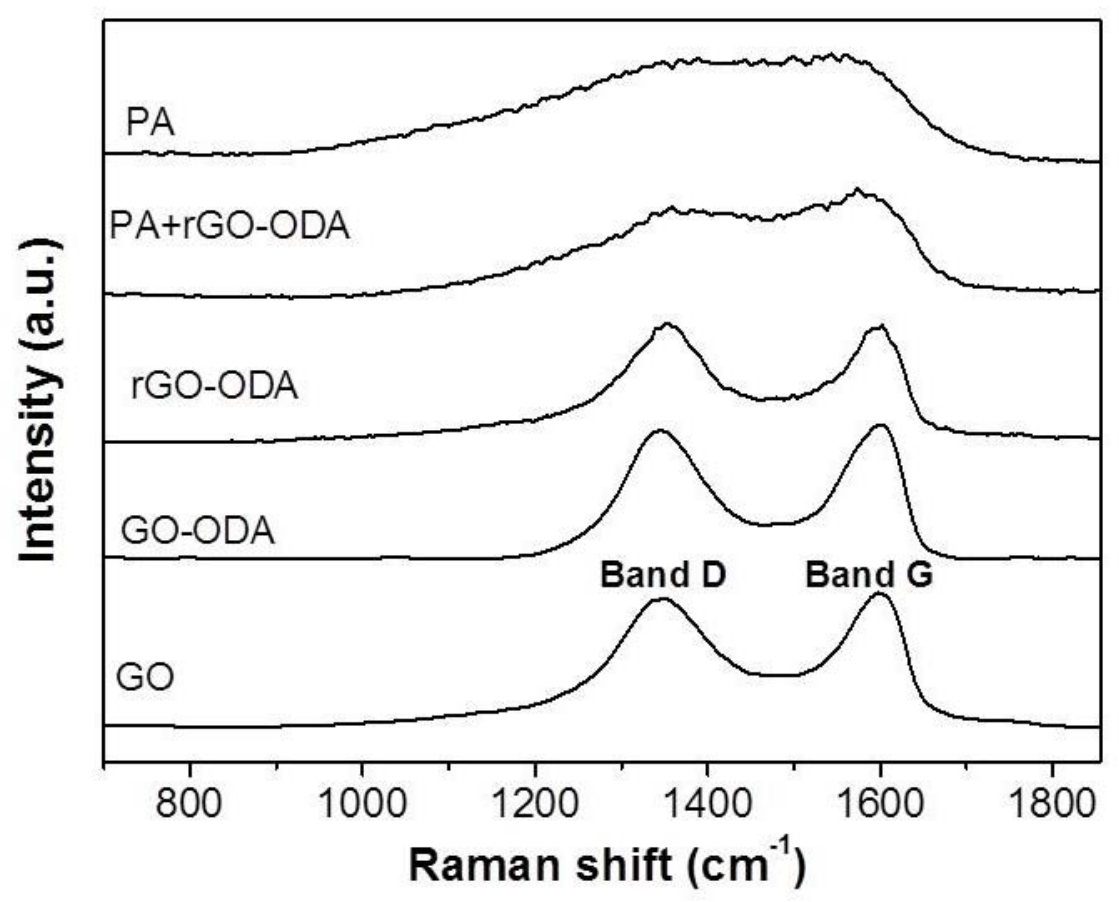

Figure 3. Raman spectra of GO, GO-ODA, rGO-ODA, PA with $0.06 \%$ (w/v) of rGOODA and PA.

GO, GO-ODA and rGO-ODA were also characterized by TGA. Figure $2 \mathrm{~b}$ shows the thermogravimetry curves obtained for the three materials. In the GO curve four weight losses can be seen: up to $130^{\circ} \mathrm{C}$ due to the evaporation of adsorbed water in the GO sheet, from $130{ }^{\circ} \mathrm{C}$ to $200{ }^{\circ} \mathrm{C}$ owing to the decomposition of the labile oxygen-containing functional groups, from $200{ }^{\circ} \mathrm{C}$ to $500{ }^{\circ} \mathrm{C}$ ascribed to more stable oxygen-containing functional groups and finally from $500{ }^{\circ} \mathrm{C}$ to $550{ }^{\circ} \mathrm{C}$ due to the combustion of the carbon skeleton $[28,42]$. The step owing to the adsorbed water is smaller for GO-ODA curve than for GO curve and almost nonexistent for rGO-ODA curve, indicating the hydrophobic character of this last material. For GO-ODA samples, Lin et al. reported [46] the existence of two weight losses related to ODA, one due to the physically bonded ODA $\left(150-180{ }^{\circ} \mathrm{C}\right)$ and the other due to the covalently bonded ODA $\left(180-500{ }^{\circ} \mathrm{C}\right)$. For the GOODA curve, the existence of a weight losses from $150{ }^{\circ} \mathrm{C}$ to $200{ }^{\circ} \mathrm{C}$ is due to the physically 
bonded ODA and labile oxygen-containing functional groups. In the case of rGO-ODA, this peak disappears due to the reduction of oxygenated groups and the elimination of physisorbed ODA. For both samples (GO-ODA and rGO-ODA), the covalently bonded ODA $\left(200-480^{\circ} \mathrm{C}\right)$ is observed. Finally, for both samples, the last weight loss could be attributed to the contribution of the combustion of the remained carbon skeleton. Figure 4 depicts a SEM image of the synthesized rGO-ODA where it is possible to see its sheet type morphology.

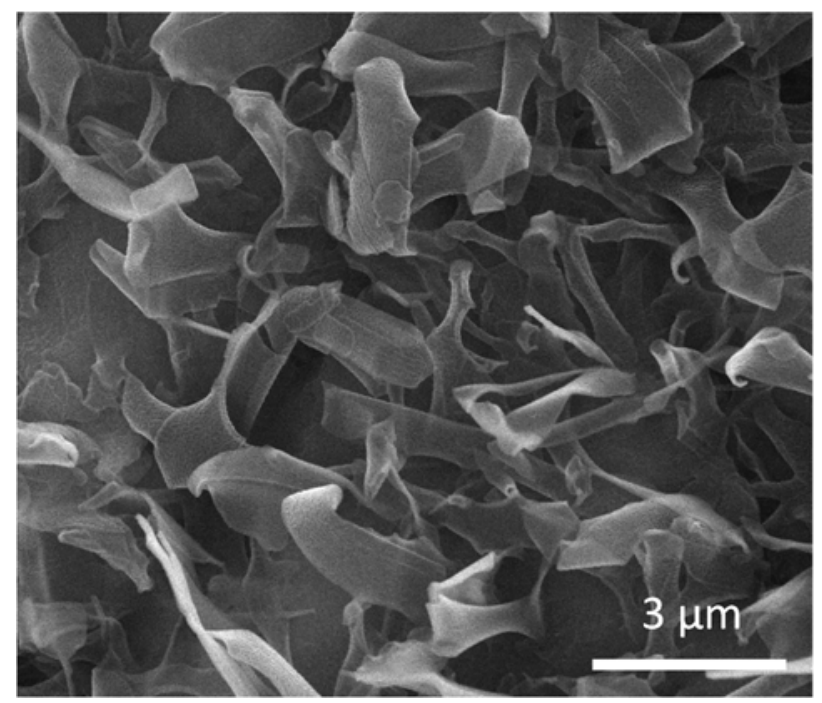

Figure 4. SEM image of rGO-ODA

\subsection{Membrane Characterization}

rGO-ODA was used as a filler in the preparation of TFN membranes using two different concentrations in the organic phase for the interfacial polymerization: $0.03 \%(\mathrm{w} / \mathrm{v})$ and $0.06 \%(\mathrm{w} / \mathrm{v})(1)$. Figure 5a shows the XRD patterns of the synthesized membranes and rGO-ODA. In the case of TFN membranes, no peaks belonging to rGO-ODA were detectable. This is due to the low quantity of rGO-ODA present in the PA layer, not enough to be able to diffract and thus be detected by XRD, and not to the loss of crystal structure of the filler during the membrane preparation procedure, as will be shown below. 

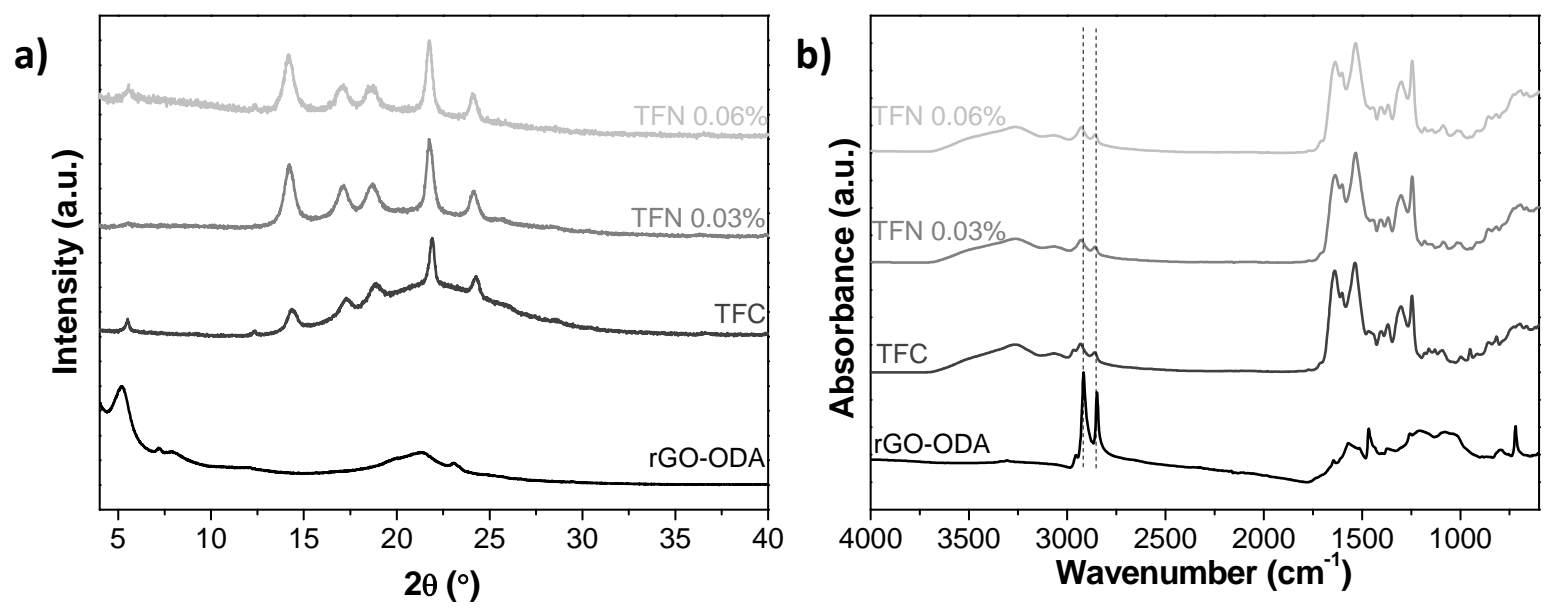

Figure 5. a) XRD pattern and b) ATR-FTIR spectra of the synthesized rGO-ODA powder, the PA TFC membrane and TFN membranes prepared in this work.

The ATR-FTIR spectra of the rGO-ODA, TFC membrane and TFN membranes appear in Figure 5b. For TFN membranes, two peaks appear at $2926 \mathrm{~cm}^{-1}$ and $2855 \mathrm{~cm}^{-1}$ which are nearly at the same wavenumbers corresponding to the two characteristic peaks present in the TFC membrane. This makes difficult to assign those absorbances to the presence of rGO-ODA in the TFN membranes.

In order to corroborate the presence of rGO-ODA into the polyamide layer, Raman spectroscopy was carried out over a piece of PA+rGO-ODA detached during IP synthesis of the TFN with $0.06 \%(\mathrm{w} / \mathrm{v})$ of rGO-ODA. As Figure 3 exhibits, PA does not show peaks between 800 and $2000 \mathrm{~cm}^{-1}$. However, the introduction of rGO-ODA in the TFN membrane gave rise to two peaks (the $\mathrm{D}$ and $\mathrm{G}$ bands above mentioned) belonging to rGO-ODA, confirming its presence in the PA film.

SEM images of the TFN membranes are shown in Figure 6a,b. The membrane surface shows a typical "ring-like" morphology indicating the PA thin layer has been correctly synthesized. Besides, no agglomerates are visible to the naked eye, which suggests that the filler was well dispersed during the synthesis of the thin PA layer [17, 36]. Figure 6c,d,e shows TEM images of the PA+rGO-ODA top layer where it is possible to 
distinguish that the flakes of rGO-ODA, maintaining their high aspect ratio, are well integrated into the PA layer synthesized by IP. Selected area electron diffraction (SAED) was used to investigate the presence of rGO-ODA flakes in the thin PA layer. As shown in Figure 6f, clear diffraction spots confirm the crystalline structure of the rGO-ODA flakes. The 6-fold pattern is consistent with a hexagonal lattice and the spots have been labelled accordingly using the Miller (hkl) indexes, equivalent to the graphite reflections $[47,48]$. They correspond to (1 - 10$)-,\left(\begin{array}{lll}0 & -1 & 1\end{array}\right)-,\left(\begin{array}{lll}-1 & 1 & 0\end{array}\right)$-type reflections and (2-1-1)-, (121)-, (-1-12)-, (-211)-type reflections, with average d-spacings of $4.8 \AA$ and $2.7 \AA$, respectively. These reflections are distinctive of the reduced graphene oxide features which remain in rGO-ODA [49]. The increment of the interlayer spacing from the intercalation of ODA molecules was not detected in the SAED pattern.

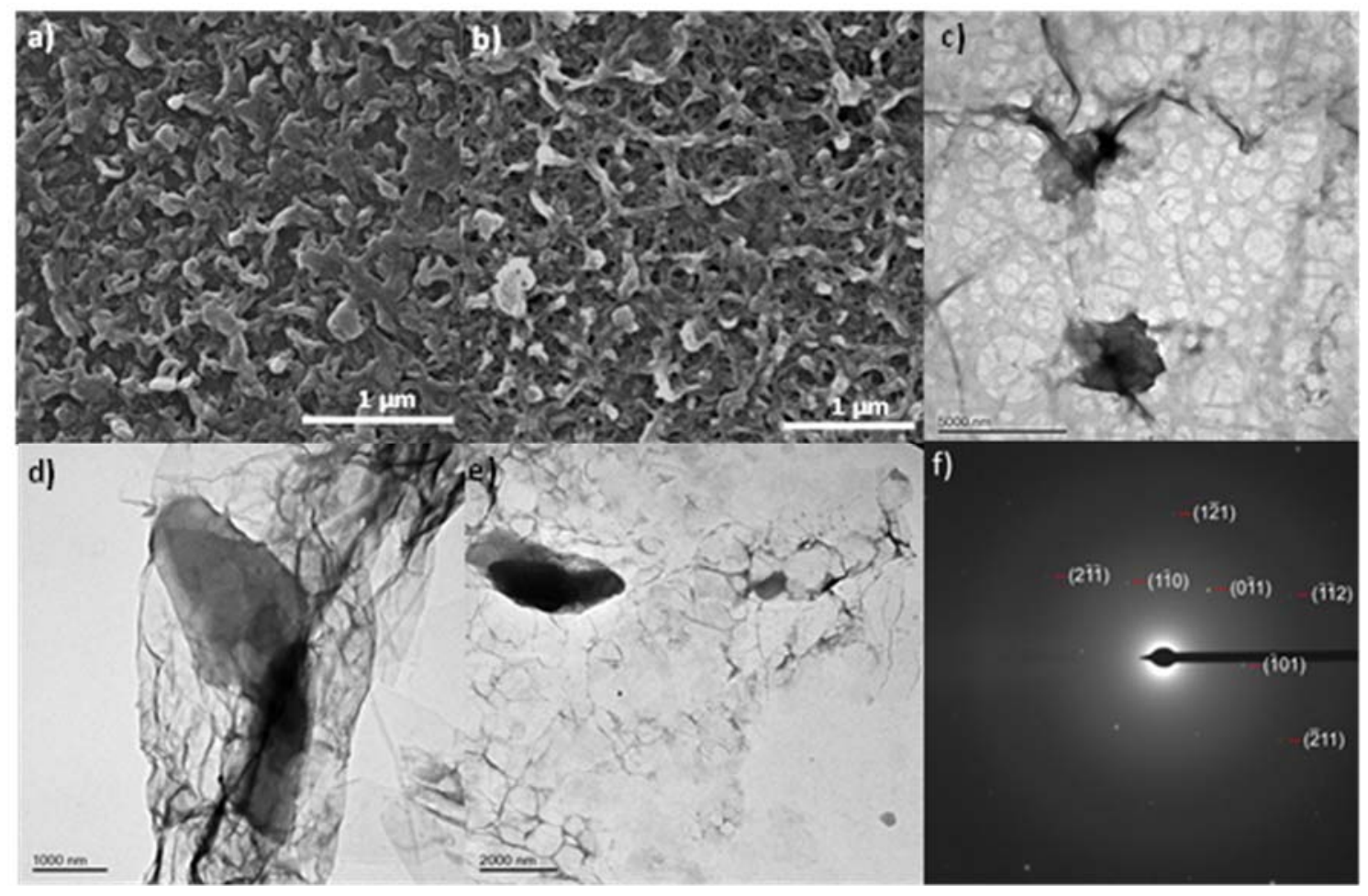

Figure 6. a,b) SEM images of TFN membranes with $0.03 \%(w / v)$ of rGO-ODA (a) and $0.06 \%(\mathrm{w} / \mathrm{v})$ of rGO-ODA (b). c, d, e) TEM images of the PA thin film with the rGOODA embedded. f) SAED pattern of (e). 
The hydrophobic/hydrophilic character of the synthesized membranes was evaluated by water contact angle. Table 1 depicts the results obtained for the TFC membrane and for the TFN membranes using $0.03 \%(\mathrm{w} / \mathrm{v})$ and $0.06 \%(\mathrm{w} / \mathrm{v})$ of rGO-ODA. With the introduction of the rGO-ODA the contact angle of the membranes increased, indicating that the TFN membranes are more hydrophobic than the TFC ones. As Alberto et al. reported [34], this is due to the fact that rGO-ODA is hydrophobic, which has been also confirmed in this work by TGA.

Table 1. $\%$ content of rGO-ODA and contact angle of the synthesized membranes.

\begin{tabular}{|c|c|c|}
\hline Membrane & \% rGO-ODA (w/v) & Contact angle $\left(^{\circ}\right)$ \\
\hline TFC & 0 & $70 \pm 1$ \\
\hline TFN $0.03 \%$ & 0.03 & $81 \pm 3$ \\
\hline TFN $0.06 \%$ & 0.06 & $84 \pm 2$ \\
\hline
\end{tabular}

\subsection{Membrane performance}

The performance of the prepared membranes was evaluated using ethanolic solutions of three dyes with distinct molecular weight as solutes: Acridine Orange (AO, $265 \mathrm{~g} \cdot \mathrm{mol}^{-1}$ ), Sunset Yellow (SY, $\left.452 \mathrm{~g} \cdot \mathrm{mol}^{-1}\right)$ and Rose Bengal $\left(\mathrm{RB}, 1017 \mathrm{~g} \cdot \mathrm{mol}^{-1}\right)$. The experiments were carried out by feeding the membranes with three consecutive solutions of AO, SY and $\mathrm{RB}$ dissolved in ethanol.

Figure 7 shows the OSN performance obtained. As can be seen, the permeance for each of the three filtrations with the three types of dyes is always higher for the TFN than for the bare TFC membrane. As previously reported [50], the interlayer space present in the rGO-ODA may provide additional pathways for the passage of the solvent, thus 
producing an increase in the permeance. The higher the concentration of rGO-ODA, the more pathways are added and the higher the permeance. This phenomenon is in agreement with the trend reported in literature, where several studies have demonstrated that the addition of certain fillers during the synthesis of the PA layer improve the membrane performance $[14,17,36,51]$. The highest permeance was achieved when the highest concentration of rGO-ODA, i.e. $0.06 \%(\mathrm{w} / \mathrm{v})$, was used, increasing from $2.8 \mathrm{~L} \mathrm{~m}^{-}$ ${ }^{2} \mathrm{~h}^{-1}$ bar $^{-1}$ for the bare TFC membrane to $4.3 \mathrm{~L} \mathrm{~m}^{-2} \mathrm{~h}^{-1}$ bar $^{-1}$ for the TFN (a $54 \%$ of improvement) when the ethanol solution containing AO was filtered. An increase from 3.4 $\mathrm{L} \mathrm{m}^{-2} \mathrm{~h}^{-1}$ bar $^{-1}$ to $4.6 \mathrm{~L} \mathrm{~m}^{-2} \mathrm{~h}^{-1}$ bar $^{-1}$ for SY (an improvement of $35 \%$ ) and from $3.7 \mathrm{~L}$ $\mathrm{m}^{-2} \mathrm{~h}^{-1}$ bar $^{-1}$ to $5.0 \mathrm{~L} \mathrm{~m}^{-2} \mathrm{~h}^{-1}$ bar $^{-1}$ for RB (a $35 \%$ of improvement) was also observed (see Table 2). This increase might be a consequence of the higher hydrophobicity of the membrane when the nanofillers are introduced in the PA layer (see Table 1) in complement with the formation of additional pathways along the gallery spaces of nontotally exfoliated rGO sheets. As seen before, the d-spacing for rGO-ODA is $1.7 \mathrm{~nm}$, far above the kinetic diameter of ethanol $(0.45 \mathrm{~nm})$. It is true that these gallery spaces in rGOODA may be partially filled with ODA molecules but they can provide simultaneously polar (amine) and non-polar (aliphatic chains) groups as in the parent GO-ODA (in this case with additional non-reacted oxygenated groups not yet reduced as in rGO-ODA) but with a less polar character, since the polarity of amide group is higher than that of amine group. In any event, this simultaneous presence of polar and non-polar groups would facilitate the transport of ethanol by jumping across the rGO-ODA galleries between sites of different polarity. In addition, small gaps between the alkyl-functionalized rGO nanosheets and the PA, as suggested by a slightly lower rejection of the smallest dye, AO, for the TNF membranes, may contribute to the ethanol transport. 


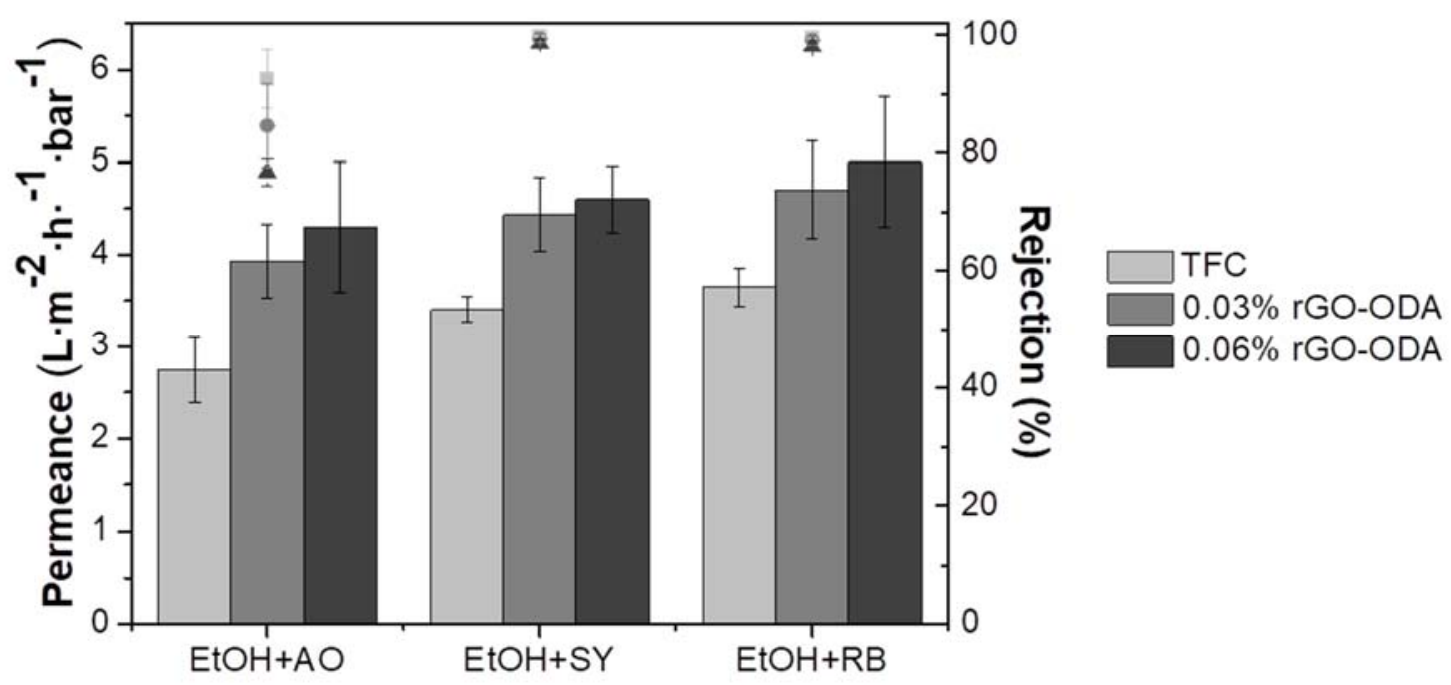

Figure 7. OSN performance of TFC, TFN $0.03 \%$ and TFN $0.06 \%$ membranes. Columns are permeance values, while symbols are rejections. Nanofiltrations were carried out at $20{ }^{\circ} \mathrm{C}$ and 20 bar. The error bars correspond to the standard deviation of the three membranes analyzed.

Table 2. Permeances and rejection using AO, SY or RB as solutes. Standard deviations have been calculated from the measurement of three membranes.

\begin{tabular}{|c|c|c|c|}
\cline { 3 - 4 } \multicolumn{2}{c|}{} & $\begin{array}{c}\text { Permeance } \\
\left(\mathbf{L} \cdot \mathbf{m}^{-2} \cdot \mathbf{h}^{-\mathbf{1}} \cdot \mathbf{b a r}^{-\mathbf{1}}\right)\end{array}$ & Rejection (\%) \\
\hline \multirow{3}{*}{ TFC } & AO & $2.8 \pm 0.4$ & $92.7 \pm 4.9$ \\
\cline { 2 - 4 } & SY & $3.4 \pm 0.1$ & $99.9 \pm 0.1$ \\
\cline { 2 - 4 } & RB & $3.7 \pm 0.2$ & $99.7 \pm 0.3$ \\
\hline \multirow{3}{*0.03\%}{ rGO-ODA } & AO & $3.9 \pm 0.4$ & $84.7 \pm 7.1$ \\
\cline { 2 - 4 } & SY & $4.4 \pm 0.4$ & $99.4 \pm 0.7$ \\
\cline { 2 - 4 } & RB & $4.7 \pm 0.5$ & $99.1 \pm 0.9$ \\
\hline \multirow{3}{*0.06\%~rGO-ODA}{} & AO & $4.3 \pm 0.7$ & $76.8 \pm 2.3$ \\
\cline { 2 - 4 } & SY & $4.6 \pm 0.4$ & $98.6 \pm 0.6$ \\
\cline { 2 - 4 } & RB & $5.0 \pm 0.7$ & $98.1 \pm 0.1$ \\
\hline
\end{tabular}

In fact, it is possible to see in Figure 7 and more clearly in Table 2, that generally the rejection in TFN membranes is lower than in TFC membranes especially the rejection corresponding to the smallest dye, AO. This can be due to the fact that the introduction of rGO-ODA, which is a laminar material, may provoke the creation of defects in the thin PA layer that allow the dye pass through [15]. 
It should be noted, that the experiments of the three solutes tested have been performed consecutively. As can be seen in Figure 7, the variation in ethanol permeation is negligible, which indicates membrane stability under operating conditions.

As can be seen in Table 3, several studies have reported the use of different kinds of membranes for their application in OSN. Due to the fact that the materials used and the nanofiltrated solutes and solvents are not the same, it is difficult to compare them. However, our ethanol permence values are amogst the highest when comparing PA TFN membranes prepared on PI P84® supports.

Table 3. Performance of different membranes applied in OSN.

\begin{tabular}{|c|c|c|c|c|c|}
\hline Membrane $^{a}$ & Filler & Feed $^{b}$ & $\begin{array}{l}\text { Permeance } \\
\left(\mathbf{L} \cdot \mathbf{m}^{-2} \cdot \mathbf{h}^{-}\right. \\
\left.1 \cdot \mathbf{b a r}^{-1}\right)\end{array}$ & $\begin{array}{l}\text { Rejection } \\
\text { (\%) }\end{array}$ & Ref. \\
\hline $\begin{array}{c}\text { Crosslinked ISA } \\
\text { membranes of } \\
\text { P84 }{ }^{\circledR} \\
\end{array}$ & $\mathrm{n} / \mathrm{a}$ & $\mathrm{PS}+\mathrm{MeOH}$ & 0.83 & 85 & {$[52]$} \\
\hline $\begin{array}{c}\text { Crosslinked ISA } \\
\text { membranes of } \\
\text { PEEK }\end{array}$ & $\mathrm{n} / \mathrm{a}$ & $\mathrm{RB}+\mathrm{IPA}$ & 0.12 & 88.0 & [53] \\
\hline \multirow{4}{*}{$\begin{array}{c}\text { Polyamide TFN } \\
\text { membranes } \\
\text { supported on P84 }\end{array}$} & MIL-53(Al) & \multirow{4}{*}{$\mathrm{PS}+\mathrm{MeOH}$} & 1.9 & 100.0 & \multirow{4}{*}[36]{} \\
\hline & $\begin{array}{c}\mathrm{NH}_{2}-\mathrm{MIL}- \\
53(\mathrm{Al}) \\
\end{array}$ & & 1.8 & 99.8 & \\
\hline & ZIF-8 & & 2.1 & 99.1 & \\
\hline & MIL-101(Cr) & & 3.9 & 98.3 & \\
\hline \multirow{3}{*}{$\begin{array}{c}\text { Polyamide TFN } \\
\text { membranes } \\
\text { supported on P84 }\end{array}$} & MIL-68(Al) & \multirow{3}{*}{$\mathrm{SY}+\mathrm{MeOH}$} & 4.4 & 93.8 & \multirow{3}{*}[17]{} \\
\hline & MIL-101(Cr) & & 4.6 & 95 & \\
\hline & ZIF-11 & & 6.2 & 91.5 & \\
\hline $\begin{array}{c}\text { Polypyrrole TFN } \\
\text { membranes } \\
\text { supported on PAN }\end{array}$ & $\mathrm{GO}$ & $\mathrm{RB}+\mathrm{MeOH}$ & 15.3 & 98.5 & {$[54]$} \\
\hline $\begin{array}{l}\text { Polyethyleneimine } \\
\text { TFN membranes } \\
\text { supported on PAN }\end{array}$ & $\begin{array}{c}\text { Functionalized } \\
\qquad \mathrm{SiO}_{2}\end{array}$ & $\mathrm{PEG}+\mathrm{MeOH}$ & 3.1 & 84.0 & {$[55]$} \\
\hline $\begin{array}{l}\text { ISA membranes of } \\
\text { PBI }\end{array}$ & $\mathrm{GO}$ & \multirow{2}{*}{$\mathrm{MB}+\mathrm{MeOH}$} & 48.5 & 93.0 & \multirow{2}{*}[56]{} \\
\hline $\begin{array}{l}\text { Crosslinked ISA } \\
\text { membranes of PBI }\end{array}$ & $\mathrm{GO}$ & & 16.9 & 98.3 & \\
\hline \multirow{4}{*}{$\begin{array}{c}\text { PDMS-based } \\
\text { Mixed matrix } \\
\text { membranes } \\
(\mathrm{MMMs})\end{array}$} & HKUST-1 & \multirow{4}{*}{$\mathrm{RB}+\mathrm{IPA}$} & 0.5 & 95.6 & \multirow{4}{*}[57]{} \\
\hline & MIL-47(V) & & 0.5 & 99.0 & \\
\hline & MIL-53(Al) & & 0.5 & 99.0 & \\
\hline & ZIF-8 & & 0.5 & 92.0 & \\
\hline
\end{tabular}




\begin{tabular}{|c|c|c|c|c|c|}
\hline $\begin{array}{c}\text { Polyamide TFN } \\
\text { membranes } \\
\text { supported on P84 }\end{array}$ & SNW-1 & $\mathrm{RDB}+\mathrm{EtOH}$ & 8.1 & 99.5 & {$[58]$} \\
\hline $\begin{array}{c}\text { Polyimide TFN } \\
\text { membranes } \\
\text { supported on P84 }\end{array}$ & GQDs & $\mathrm{RDB}+\mathrm{EtOH}$ & 2.3 & 98.6 & [59] \\
\hline $\begin{array}{c}\text { Polyamide TFN } \\
\text { membranes } \\
\text { supported on P84 }\end{array}$ & $\mathrm{UiO}-66-\mathrm{NH}_{2}$ & $\mathrm{TC}+\mathrm{MeOH}$ & 20 & 99.0 & {$[60]$} \\
\hline $\begin{array}{c}\text { Polyamide TFN } \\
\text { membranes } \\
\text { supported on P84 }\end{array}$ & $\begin{array}{c}\text { Interlayered } \\
\text { GO }\end{array}$ & $\mathrm{RDB}+\mathrm{EtOH}$ & 4.2 & 99.4 & {$[60]$} \\
\hline \multirow{3}{*}{$\begin{array}{c}\text { Polyamide TFN } \\
\text { membranes } \\
\text { supported on P84 }\end{array}$} & \multirow{3}{*}{ rGO-ODA } & $\mathrm{AO}+\mathrm{EtOH}$ & 4.3 & 76.8 & \multirow{3}{*}{$\begin{array}{l}\text { This } \\
\text { work }\end{array}$} \\
\hline & & $\mathrm{SY}+\mathrm{EtOH}$ & 4.6 & 98.6 & \\
\hline & & $\mathrm{RB}+\mathrm{EtOH}$ & 5.0 & 98.1 & \\
\hline
\end{tabular}

ISA: integrally skinned asymmetric, TFC: thin film composite, TFN: thin film nanocomposite, PAN: polyacrylonitrile, PBI: polybenzimidazole, MMM: mixed matrix membrane.

bPS: polystyrene $\left(400 \mathrm{~g} \cdot \mathrm{mol}^{-1}\right), \mathrm{RB}$ : rose bengal $\left(974 \mathrm{~g} \cdot \mathrm{mol}^{-1}\right)$, SY: sunset yellow (452 $\left.\mathrm{g} \cdot \mathrm{mol}^{-1}\right)$, PEG: polyethylene glycol $\left(400 \mathrm{~g} \cdot \mathrm{mol}^{-1}\right), \mathrm{MB}:$ mepenzolate bromide $\left(420 \mathrm{~g} \cdot \mathrm{mol}^{-}\right.$ $\left.{ }^{1}\right)$, RDB: rhodamine B $\left(479 \mathrm{~g} \cdot \mathrm{mol}^{-1}\right)$, TC: tetracycline $\left(444 \mathrm{~g} \cdot \mathrm{mol}^{-1}\right)$, AO: acridine orange $\left(265 \mathrm{~g} \cdot \mathrm{mol}^{-1}\right)$.

The nanofiltration of an aqueous solution of acridine orange (AO) has been carried out with our membranes in order to compare our results with those in the literature using membranes with GO in nanofiltration or reverse osmosis. At the $0.06 \%(\mathrm{w} / \mathrm{v})$ concentration of rGO-ODA, the water permeance increased from $6.8 \pm 0.3 \mathrm{~L} \mathrm{~m}^{-2} \mathrm{~h}^{-1} \mathrm{bar}^{-1}$ for the bare TFC membrane to $8.9 \pm 1.3 \mathrm{~L} \mathrm{~m}^{-2} \mathrm{~h}^{-1} \mathrm{bar}^{-1}$ for the TFN membrane, while the rejection decreased when the filler was introduced from $99.0 \pm 0.4 \%$ for the bare TFC membrane to $96.4 \%$ for the TFN membrane. The permeance values and their increase when introducing the filler are of the order of those found in literature (Table 4). Regarding the rejection, the tested molecules in the literature (Table 4) are very diverse but generally the high rejection values are maintained when the filler is introduced in the selective layer.

Table 4. Performance of different graphene oxide (GO) enhanced polyamide (PA) thinfilm nanocomposite (TFN) membranes and PA thin film composite (TFC) membranes applied for nanofiltration/reverse osmosis using water 


\begin{tabular}{|c|c|c|c|c|c|c|}
\hline $\begin{array}{l}\text { Support } \\
\text { material }^{\mathrm{a}}\end{array}$ & Filler $^{b}$ & Solute ${ }^{c}$ & $\begin{array}{c}\text { Membrane } \\
\text { type }\end{array}$ & $\begin{array}{c}\text { Permeance } \\
\left(\mathbf{L} \cdot \mathbf{m}^{-2} \cdot \mathbf{h}^{-}\right. \\
\left.1 \cdot \mathbf{b a r}^{-1}\right)\end{array}$ & $\begin{array}{c}\text { Rejection } \\
(\%)\end{array}$ & Ref. \\
\hline \multirow{2}{*}{ PSF } & \multirow{2}{*}{$\mathrm{GO}$} & \multirow{2}{*}{$\begin{array}{c}\mathrm{NaCl} / \\
\mathrm{Na}_{2} \mathrm{SO}_{4} \\
\end{array}$} & TFC & 1.88 & $96 / 98$ & \multirow{2}{*}{ [15] } \\
\hline & & & TFN & 2.87 & $94 / 97$ & \\
\hline \multirow{2}{*}{ PSF } & \multirow{2}{*}{ GO } & \multirow{2}{*}{$\mathrm{NaCl}$} & TFC & 0.59 & 99 & \multirow{2}{*}{ [27] } \\
\hline & & & TFN & 1.03 & 99 & \\
\hline \multirow[b]{2}{*}{ PSF } & \multirow{2}{*}{$\begin{array}{c}\text { GO } \\
\text { Quantum } \\
\text { dots }\end{array}$} & \multirow[b]{2}{*}{$\mathrm{NaCl}$} & TFC & 1.54 & 99 & \multirow[b]{2}{*}{ [29] } \\
\hline & & & TFN & 2.34 & 99 & \\
\hline \multirow{2}{*}{ PES } & \multirow{2}{*}{ ZIF-8/GO } & \multirow{2}{*}{$\mathrm{Na}_{2} \mathrm{SO}_{4}$} & TFC & 2.70 & 100 & \multirow{2}{*}{ [30] } \\
\hline & & & TFN & 4.12 & 100 & \\
\hline \multirow{2}{*}{ PES } & \multirow{2}{*}{ GO-PSBM } & \multirow{2}{*}{$\begin{array}{l}\mathrm{NaCl} / \\
\mathrm{MgSO}_{4}\end{array}$} & TFC & 0.17 & $98 / 100$ & \multirow{2}{*}{ [31] } \\
\hline & & & TFN & 0.4 & $94 / 98$ & \\
\hline \multirow{2}{*}{ PES } & \multirow{2}{*}{ GO-ODA } & \multirow{2}{*}{$\mathrm{Na}_{2} \mathrm{SO}_{4}$} & TFC & 8.4 & 94 & \multirow{2}{*}{ [32] } \\
\hline & & & TFN & 5.5 & 98 & \\
\hline \multirow{2}{*}{ PES } & \multirow{2}{*}{$\begin{array}{c}\text { GO-HBE- } \\
\text { COOH }\end{array}$} & \multirow{2}{*}{$\mathrm{Na}_{2} \mathrm{SO}_{4}$} & TFC & 8.1 & 98 & \multirow{2}{*}{ [61] } \\
\hline & & & TFN & 5.6 & 98 & \\
\hline \multirow{2}{*}{ PSF } & \multirow{2}{*}{ MAH-GO } & \multirow{2}{*}{$\mathrm{Na}_{2} \mathrm{SO}_{4}$} & TFC & 8.3 & 98 & \multirow{2}{*}[62]{} \\
\hline & & & TFN & 4.7 & 98 & \\
\hline \multirow{2}{*}{ PI } & \multirow{2}{*}{ rGO-ODA } & \multirow{2}{*}{$\mathrm{AO}$} & TFC & 6.8 & 99. & \multirow{2}{*}{$\begin{array}{l}\text { This } \\
\text { work }\end{array}$} \\
\hline & & & TFN & 8.9 & 96 & \\
\hline
\end{tabular}

aPSF: polysulfone. PES: polyether sulfone. PI: polyimide.

'PSBM: poly(sulfobetaine methacrylate). ODA: octadecylamine. HBE: hyperbranched Polymers. MAH: maleic anhydride. rGO: reduced graphene oxide.

'Acridine orange

\section{Conclusions}

The fabrication of TFN membranes using rGO has been carried out for their application in nanofiltration. First, the successful functionalization and reduction of GO was verified by different techniques. In the FTIR spectrum of rGO-ODA new peaks appeared in comparison to the starting GO due to the functionalities of ODA. The XRD pattern showed an interlayer space in rGO-ODA higher than in GO due to the intercalation of ODA. The changes observed in the Raman spectra and in the TGA curves corroborated the expected functionalization.

In the case of TFN membranes, the little amount of rGO-ODA present in the membrane made its detection by FTIR and XRD not possible. As a way to assess the presence of rGO-ODA into the PA layer, a detached piece of PA layer (with embedded rGO-ODA 
filler) was characterized by Raman, TEM and electron diffraction. The Raman spectrum of the PA+rGO-ODA showed two peaks not present in the Raman spectrum of PA that correspond to rGO-ODA. TEM images allowed to distinguish flakes of rGO-ODA in the PA layer, whereas thanks to electron diffraction it was possible to obtain the characteristic plane diffraction of rGO-ODA. This confirmed the presence of rGO-ODA in the TFN membrane and thus the maintenance of its crystalline structure during the interfacial polymerization.

The synthesized membranes were applied to the nanofiltration of ethanol solutions of AO, SY and RB dyes. The better performance was obtained with TFN membranes in all cases, with the best results in case of $0.06 \%(\mathrm{w} / \mathrm{v})$ of rGO-ODA and with ethanol permeances in the range of 4.3-5.0 $\mathrm{L} \mathrm{m}^{-2} \mathrm{~h}^{-1} \mathrm{bar}^{-1}$, depending on the tested dye (AO, SY and RB). This means a $35-54 \%$ of permeance enhancement as compared to the unmodified PA membrane and without compromising the rejection particularly for SY and RB. The increase of the ethanol flux achieved with the rGO-ODA (a filler that decreased the hydrophilicity of the membrane) based TFN membrane was due to a combination of the simultaneous presence of polar and non-polar groups from rGO-ODA nanosheets and the creation of gaps between such rGO-ODA particles and the polyamide of the membrane skin layer.

\section{Declaration of Competing Interest}

The authors declare no conflict of interest.

\section{Acknowledgements}

Financial support from the Research Project MAT2016-77290-R (MINECO/AEI/FEDER, UE) is gratefully acknowledged. The Aragón Government 
(T43-17R) and the ESF is also gratefully acknowledged. Lorena Paseta would like to express her gratitude to the Spanish MINECO for the predoctoral grant (BES-2014068287) awarded, and to Fernando Cazaña and Monica Alberto for helping with the Raman characterization. All the microscopy work was done in the Laboratorio de Microscopías Avanzadas at the Instituto de Nanociencia de Aragón (LMA-INA). Finally, the authors would like to acknowledge the use of the Servicio General de Apoyo a la Investigación-SAI, Universidad de Zaragoza.

\section{References}

[1] P. Marchetti, M.F. Jimenez Solomon, G. Szekely, A.G. Livingston, Molecular Separation with Organic Solvent Nanofiltration: A Critical Review, Chem. Rev., 114 (2014) 10735-10806.

[2] J. Radjenović, M. Petrović, F. Ventura, D. Barceló, Rejection of pharmaceuticals in nanofiltration and reverse osmosis membrane drinking water treatment, Water Res., 42 (2008) 3601-3610.

[3] K. Košutić, L. Furač, L. Sipos, B. Kunst, Removal of arsenic and pesticides from drinking water by nanofiltration membranes, Sep. Purif. Technol., 42 (2005) 137-144.

[4] R. Castro-Munoz, J. Yanez-Fernandez, V. Fila, Phenolic compounds recovered from agrofood by-products using membrane technologies: An overview, Food Chemistry, 213 (2016) 753-762.

[5] V. Yangali-Quintanilla, S.K. Maeng, T. Fujioka, M. Kennedy, Z. Li, G. Amy, Nanofiltration vs. reverse osmosis for the removal of emerging organic contaminants in water reuse, Desalination Water Treat., 34 (2011) 50-56.

[6] S. Darvishmanesh, L. Firoozpour, J. Vanneste, P. Luis, J. Degrève, B.V.d. Bruggen, Performance of solvent resistant nanofiltration membranes for purification of residual solvent in the pharmaceutical industry: experiments and simulation, Green Chem., 13 (2011) 34763483.

[7] A.V. Volkov, G.A. Korneeva, F.T. Gennadii, Organic solvent nanofiltration: prospects and application, Russ. Chem. Rev., 77 (2008) 983.

[8] D. Peshev, L.G. Peeva, G. Peev, I.I.R. Baptista, A.T. Boam, Application of organic solvent nanofiltration for concentration of antioxidant extracts of rosemary (Rosmarinus officiallis L.), Chem. Eng. Res. Des., 89 (2011) 318-327.

[9] R.J. Petersen, Composite reverse osmosis and nanofiltration membranes, J. Membr. Sci., 83 (1993) 81-150.

[10] E.M. Rundquist, Application and Evaluation of Organic Solvent Nanofiltration in Pharmaceutical Processing Department of Chemical Engineering and Chemical Technology, Imperial College London, 2013.

[11] W.J. Lau, A.F. Ismail, N. Misdan, M.A. Kassim, A recent progress in thin film composite membrane: A review, Desalination, 287 (2012) 190-199.

[12] B.-H. Jeong, E.M.V. Hoek, Y. Yan, A. Subramani, X. Huang, G. Hurwitz, A.K. Ghosh, A. Jawor, Interfacial polymerization of thin film nanocomposites: A new concept for reverse osmosis membranes, J. Membr. Sci., 294 (2007) 1-7. 
[13] I. Soroko, A. Livingston, Impact of TiO2 nanoparticles on morphology and performance of crosslinked polyimide organic solvent nanofiltration (OSN) membranes, J. Membr. Sci., 343 (2009) 189-198.

[14] J. Yin, E.-S. Kim, J. Yang, B. Deng, Fabrication of a novel thin-film nanocomposite (TFN) membrane containing MCM-41 silica nanoparticles (NPs) for water purification, J. Membr. Sci., 423-424 (2012) 238-246.

[15] J. Yin, G. Zhu, B. Deng, Graphene oxide (GO) enhanced polyamide (PA) thin-film nanocomposite (TFN) membrane for water purification, Desalination, 379 (2016) 93-101.

[16] J. Duan, Y. Pan, F. Pacheco, E. Litwiller, Z. Lai, I. Pinnau, High-performance polyamide thinfilm-nanocomposite reverse osmosis membranes containing hydrophobic zeolitic imidazolate framework-8, J. Membr. Sci., 476 (2015) 303-310.

[17] C. Echaide-Gorriz, S. Sorribas, C. Tellez, J. Coronas, MOF nanoparticles of MIL-68(AI), MIL$101(\mathrm{Cr})$ and ZIF-11 for thin film nanocomposite organic solvent nanofiltration membranes, RSC Adv., 6 (2016) 90417-90426.

[18] J. Sánchez-Laínez, L. Paseta, M. Navarro, B. Zornoza, C. Téllez, J. Coronas, Ultrapermeable Thin Film ZIF-8/Polyamide Membrane for H2/CO2 Separation at High Temperature without Using Sweep Gas, Adv. Mater. Interfaces, 5 (2018) 1800647.

[19] D.R. Dreyer, S. Park, C.W. Bielawski, R.S. Ruoff, The chemistry of graphene oxide, Chem. Soc. Rev., 39 (2010) 228-240.

[20] C.V. Gomez, E. Robalino, D. Haro, T. Tene, P. Escudero, A. Haro, J. Orbe, Structural and Electronic Properties of Graphene Oxide for Different Degree of Oxidation1, Mater. Today Proc., 3 (2016) 796-802.

[21] Y. Yao, X. Chen, H. Guo, Z. Wu, Graphene oxide thin film coated quartz crystal microbalance for humidity detection, Appl. Surf. Sci., 257 (2011) 7778-7782.

[22] T.-F. Yeh, C.-Y. Teng, S.-J. Chen, H. Teng, Nitrogen-Doped Graphene Oxide Quantum Dots as Photocatalysts for Overall Water-Splitting under Visible Light Illumination, Adv. Mater. (Weinheim, Ger.), 26 (2014) 3297-3303.

[23] A. Eftekhari, Y.M. Shulga, S.A. Baskakov, G.L. Gutsev, Graphene oxide membranes for electrochemical energy storage and conversion, Int. J. Hydrogen Energy, 43 (2018) 2307-2326.

[24] S. Castarlenas, C. Téllez, J. Coronas, Gas separation with mixed matrix membranes obtained from MOF UiO-66-graphite oxide hybrids, J. Membr. Sci., 526 (2017) 205-211.

[25] D.P. Singh, C.E. Herrera, B. Singh, S. Singh, R.K. Singh, R. Kumar, Graphene oxide: An efficient material and recent approach for biotechnological and biomedical applications, Mater. Sci. Eng. C, 86 (2018) 173-197.

[26] M. Doğu, N. Ercan, High performance cyclic olefin copolymer (COC) membranes prepared with melt processing method and using of surface modified graphitic nano-sheets for $\mathrm{H} 2 / \mathrm{CH} 4$ and H2/CO2 separation, Chem. Eng. Res. Des., 109 (2016) 455-463.

[27] H.-R. Chae, J. Lee, C.-H. Lee, I.-C. Kim, P.-K. Park, Graphene oxide-embedded thin-film composite reverse osmosis membrane with high flux, anti-biofouling, and chlorine resistance, J. Membr. Sci., 483 (2015) 128-135.

[28] J. Zahirifar, J. Karimi-Sabet, S.M.A. Moosavian, A. Hadi, P. Khadiv-Parsi, Fabrication of a novel octadecylamine functionalized graphene oxide/PVDF dual-layer flat sheet membrane for desalination via air gap membrane distillation, Desalination, 428 (2018) 227-239.

[29] X. Song, Q. Zhou, T. Zhang, H. Xu, Z. Wang, Pressure-assisted preparation of graphene oxide quantum dot-incorporated reverse osmosis membranes: antifouling and chlorine resistance potentials, J. Mater. Chem. A, 4 (2016) 16896-16905.

[30] J. Wang, Y. Wang, Y. Zhang, A. Uliana, J. Zhu, J. Liu, B. Van der Bruggen, Zeolitic Imidazolate Framework/Graphene Oxide Hybrid Nanosheets Functionalized Thin Film Nanocomposite Membrane for Enhanced Antimicrobial Performance, ACS Appl. Mater. Interfaces, 8 (2016) 25508-25519. 
[31] W. Ma, T. Chen, S. Nanni, L. Yang, Z. Ye, M. Rahaman, Zwitterion-Functionalized Graphene Oxide Incorporated Polyamide Membranes with Improved Antifouling Properties, Langmuir, 35 (2018) 1513-1525.

[32] S.-M. Xue, C.-H. Ji, Z.-L. Xu, Y.-J. Tang, R.-H. Li, Chlorine resistant TFN nanofiltration membrane incorporated with octadecylamine-grafted $\mathrm{GO}$ and fluorine-containing monomer, J. Membr. Sci., 545 (2018) 185-195.

[33] M. Alberto, R. Bhavsar, J.M. Luque-Alled, E. Prestat, L. Gao, P.M. Budd, A. Vijayaraghavan, G. Szekely, S.M. Holmes, P. Gorgojo, Study on the formation of thin film nanocomposite (TFN) membranes of polymers of intrinsic microporosity and graphene-like fillers: Effect of lateral flake size and chemical functionalization, J. Membr. Sci., 565 (2018) 390-401.

[34] M. Alberto, J.M. Luque-Alled, L. Gao, M. Iliut, E. Prestat, L. Newman, S.J. Haigh, A. Vijayaraghavan, P.M. Budd, P. Gorgojo, Enhanced organophilic separations with mixed matrix membranes of polymers of intrinsic microporosity and graphene-like fillers, J. Membr. Sci., 526 (2017) 437-449.

[35] M.F. Jimenez Solomon, Y. Bhole, A.G. Livingston, High flux membranes for organic solvent nanofiltration (OSN) - Interfacial polymerization with solvent activation, J. Membr. Sci., 423424 (2012) 371-382.

[36] S. Sorribas, P. Gorgojo, C. Téllez, J. Coronas, A.G. Livingston, High Flux Thin Film Nanocomposite Membranes Based on Metal-Organic Frameworks for Organic Solvent Nanofiltration, J. Am. Chem. Soc., 135 (2013) 15201-15208.

[37] J.I. Paredes, S. Villar-Rodil, A. Martínez-Alonso, J.M.D. Tascón, Graphene Oxide Dispersions in Organic Solvents, Langmuir, 24 (2008) 10560-10564.

[38] D. Konios, M.M. Stylianakis, E. Stratakis, E. Kymakis, Dispersion behaviour of graphene oxide and reduced graphene oxide, J. Colloid Interface Sci., 430 (2014) 108-112.

[39] J. Jang, V.H. Pham, S.H. Hur, J.S. Chung, Dispersibility of reduced alkylamine-functionalized graphene oxides in organic solvents, J. Colloid Interface Sci., 424 (2014) 62-66.

[40] H.P. Mungse, O.P. Khatri, Chemically Functionalized Reduced Graphene Oxide as a Novel Material for Reduction of Friction and Wear, Journal of Physical Chemistry C, 118 (2014) 14394-14402.

[41] X. Yang, T. Mei, J. Yang, C. Zhang, M. Lv, X. Wang, Synthesis and characterization of alkylamine-functionalized graphene for polyolefin-based nanocomposites, Appl. Surf. Sci., 305 (2014) 725-731.

[42] S.-P. Zhang, H.-O. Song, Supramolecular graphene oxide-alkylamine hybrid materials: variation of dispersibility and improvement of thermal stability, New J. Chem., 36 (2012) 17331738.

[43] S. Zhang, P. Xiong, X. Yang, X. Wang, Novel PEG functionalized graphene nanosheets: enhancement of dispersibility and thermal stability, Nanoscale, 3 (2011) 2169-2174.

[44] S. Stankovich, D.A. Dikin, R.D. Piner, K.A. Kohlhaas, A. Kleinhammes, Y. Jia, Y. Wu, S.T. Nguyen, R.S. Ruoff, Synthesis of graphene-based nanosheets via chemical reduction of exfoliated graphite oxide, Carbon, 45 (2007) 1558-1565.

[45] C.H. Xu, J. Li, X.B. Wang, J.C. Wang, L. Wan, Y.Y. Li, M. Zhang, X.P. Shang, Y.K. Yang, Synthesis of hemin functionalized graphene and its application as a counter electrode in dyesensitized solar cells, Materials Chemistry and Physics, 132 (2012) 858-864.

[46] Z. Lin, Y. Liu, C.-p. Wong, Facile Fabrication of Superhydrophobic OctadecylamineFunctionalized Graphite Oxide Film, Langmuir, 26 (2010) 16110-16114.

[47] J.C. Meyer, A.K. Geim, M.I. Katsnelson, K.S. Novoselov, D. Obergfell, S. Roth, C. Girit, A. Zettl, On the roughness of single- and bi-layer graphene membranes, Solid State Commun., 143 (2007) 101-109.

[48] N.R. Wilson, P.A. Pandey, R. Beanland, R.J. Young, I.A. Kinloch, L. Gong, Z. Liu, K. Suenaga, J.P. Rourke, S.J. York, J. Sloan, Graphene Oxide: Structural Analysis and Application as a Highly Transparent Support for Electron Microscopy, ACS Nano, 3 (2009) 2547-2556. 
[49] H.P. Mungse, R. Singh, H. Sugimura, N. Kumar, O.P. Khatri, Molecular pillar supported graphene oxide framework: conformational heterogeneity and tunable d-spacing, Phys. Chem. Chem. Phys., 17 (2015) 20822-20829.

[50] Q. Yang, Y. Su, C. Chi, C.T. Cherian, K. Huang, V.G. Kravets, F.C. Wang, J.C. Zhang, A. Pratt, A.N. Grigorenko, F. Guinea, A.K. Geim, R.R. Nair, Ultrathin graphene-based membrane with precise molecular sieving and ultrafast solvent permeation, Nat. Mater., 16 (2017) 1198.

[51] H.S. Lee, S.J. Im, J.H. Kim, H.J. Kim, J.P. Kim, B.R. Min, Polyamide thin-film nanofiltration membranes containing TiO2 nanoparticles, Desalination, 219 (2008) 48-56.

[52] Y.H. See Toh, F.W. Lim, A.G. Livingston, Polymeric membranes for nanofiltration in polar aprotic solvents, J. Membr. Sci., 301 (2007) 3-10.

[53] K. Hendrix, M. Van Eynde, G. Koeckelberghs, I.F.J. Vankelecom, Crosslinking of modified poly(ether ether ketone) membranes for use in solvent resistant nanofiltration, J. Membr. Sci., 447 (2013) 212-221.

[54] L. Shao, X. Cheng, Z. Wang, J. Ma, Z. Guo, Tuning the performance of polypyrrole-based solvent-resistant composite nanofiltration membranes by optimizing polymerization conditions and incorporating graphene oxide, J. Membr. Sci., 452 (2014) 82-89.

[55] Y. Li, H. Mao, H. Zhang, G. Yang, R. Ding, J. Wang, Tuning the microstructure and permeation property of thin film nanocomposite membrane by functionalized inorganic nanospheres for solvent resistant nanofiltration, Sep. Purif. Technol., 165 (2016) 60-70.

[56] F. Fei, L. Cseri, G. Szekely, C.F. Blanford, Robust Covalently Cross-linked Polybenzimidazole/Graphene Oxide Membranes for High-Flux Organic Solvent Nanofiltration, ACS Appl. Mater. Interfaces, 10 (2018) 16140-16147.

[57] S. Basu, M. Maes, A. Cano-Odena, L. Alaerts, D.E. De Vos, I.F.J. Vankelecom, Solvent resistant nanofiltration (SRNF) membranes based on metal-organic frameworks, J. Membr. Sci., 344 (2009) 190-198.

[58] C. Li, S.X. Li, L. Tian, J.M. Zhang, B.W. Su, M.Z. Hu, Covalent organic frameworks (COFs)incorporated thin film nanocomposite (TFN) membranes for high-flux organic solvent nanofiltration (OSN), Journal of Membrane Science, 572 (2019) 520-531.

[59] S.X. Li, C. Li, X.J. Song, B.W. Su, B. Mandal, B. Prasad, X.L. Gao, C.J. Gao, Graphene Quantum Dots-Doped Thin Film Nanocomposite Polyimide Membranes with Enhanced Solvent Resistance for Solvent-Resistant Nanofiltration, Acs Applied Materials \& Interfaces, 11 (2019) 6527-6540.

[60] X.Y. Guo, D.H. Liu, T.T. Han, H.L. Huang, Q.Y. Yang, C.L. Zhong, Preparation of Thin Film Nanocomposite Membranes with Surface Modified MOF for High Flux Organic Solvent Nanofiltration, Aiche Journal, 63 (2017) 1303-1312.

[61] Q.L. Xie, S.S. Zhang, H.J. Ma, W.Y. Shao, X. Gong, Z.A. Hong, A Novel Thin-Film Nanocomposite Nanofiltration Membrane by Incorporating 3D Hyperbranched Polymer Functionalized 2D Graphene Oxide, Polymers, 10 (2018).

[62] Q.L. Xie, W.Y. Shao, S.S. Zhang, Z. Hong, Q.Q. Wang, B.R. Zeng, Enhancing the performance of thin-film nanocomposite nanofiltration membranes using MAH-modified GO nanosheets, Rsc Advances, 7 (2017) 54898-54910. 